\title{
Bibliometric practices and activities at the University of Vienna
}

\author{
Christian Gumpenberger $^{1}$, Martin Wieland ${ }^{1}$ and Juan Gorraiz ${ }^{1}$ \\ ${ }^{1}$ University of Vienna, Library and Archive Services, Bibliometrics Department, Boltzmanng. 5, A-1090 Vienna
}

\begin{abstract}
:
By means of the bibliometric practices and activities at the University of Vienna this paper describes the importance of bibliometrics as an emergent field for academic librarians. It points out the manifold opportunities to provide innovative services for both academic and administrative university staff as well as to participate in the international scientific discourse. The implemented Bibliometrics Department has accepted the challenge to demonstrate its expertise and usefulness and serves as a role model for other libraries. The recently launched European Summer School for Scientometrics is a response to the lack of a pertinent education in this field which is increasingly important to fill the role of a "bibliometrics-savvy" information specialist.
\end{abstract}

Keywords: library and information science, modern librarianship, academic library, bibliometrics, bibliometric services, scientometrics, European Summer School for Scientometrics

\section{Introduction}

The first bibliometric analyses ever have been carried out by librarians (Cole and Eales, 1917; Gross and Gross, 1927). As a new discipline of library and information sciences, bibliometrics developed as a tool for measuring and monitoring scientific output. This opened the door for new scopes of application, and bibliometrics gradually transformed into scientometrics.

There is a constant need to adapt to the ongoing changes and new demands of today's information environment, and the increasing importance of bibliometrics certainly presents a great opportunity as well as a challenge for modern scientific libraries (Ball and Tunger, 2004; Gorraiz and Wieland, 2009; MacColl, 2010; Haest, 2010; Gerritsma et al., 2010). Not only by the use of bibliometric methods as an instrument to support library-oriented decisions (e.g. the selection and evaluation of monographs, journals, bibliographies, collections and databases), but also to provide whole institutions or even universities with high-quality bibliometric data (Ball and Tunger, 2004; Gorraiz et al., 2010).

\section{A perfect fit for academic libraries}

Hardly any other job description underwent as many dramatic changes within the last decades as the one of an academic librarian. Living in the era of the electronic information society paired with an increasingly competitive scientific environment, academic libraries need to immediately respond to international trends and challenges and adapt their profile of requirements accordingly. Bibliometrics and scientometrics are therefore ideal fields of activities for modern academic librarians, and the reasons are manifold:

- Librarians know how to use the major databases efficiently, and of course have access to many of these and their imposed analytical tools.

- Librarians have experience in data gathering and cleansing as well as in coding and categorizing diverse types of documents. As a result they extract meaningful information for further interpretation.

- Librarians belong to independent and interdisciplinary institutions. In this position they are predestined for providing central services tailored for scientists, research managers and science policy makers.

- Librarians do not only have the opportunity to create and implement a wealth of new services, but can furthermore contribute to the global discipline-specific scientific discourse by participating in projects and collaborations, by attending and organizing conferences and by actively publishing relevant findings.

\section{From a bibliometrics working group towards a dedicated department}

Few Austrian institutions offer professional bibliometric services so far, and the University of Vienna leads the way in Austria. On the initiative of the Vienna University Library, the inter-institutional working group "Scientometrics" was founded in spring 2007. The aim of this working group was the coordination of all organisational university units dealing with scientometric tasks (i.e. Vienna University Library, Department for Quality Assurance, Research Services and International Relations, rectorate) in order to bundle the existing competences. The working group intended to become engaged in the 
- Development of workflows and standards in the analysis and evaluation of scientific publications at individual, at institutional (departmental) or at university level

- Increase of synergetic effects according to coordinated research evaluation activities (internal research assessment documentation RAD vs. Web of Science and Scopus)

- International networking with the leading institutions in scientometrics

- Implementation of a bibliometric helpdesk for the scientific staff of the University of Vienna

A project was officially launched in summer 2007. As an outcome all the efforts taken finally resulted in the formation of a new bibliometrics department at the Vienna University Library in 2009.

The Vienna University Bibliometrics Department is now engaged in the following activities:

1. Teaching

2. Consultancy and expert analyses

3. Organisation of events

4. Development partnerships

5. Projects

6. Scientific output

\section{Ad 1.) Teaching}

The Bibliometrics Department's teaching activities are tailored to the needs of different target groups. Regularly offered scheduled database trainings are complemented by spontaneous one-on-one sessions either for students or for research staff.

Embedded in the course offerings of the Vienna University Center for Doctoral Studies, doctoral candidates are trained in the efficient use of the Web of Science twice a year. A dedicated course on bibliometrics will be additionally introduced in 2011.

Furthermore the Bibliometrics Department provides a module on bibliometrics in the university course "Library and Information Studies" and supervises corresponding projects or master theses.

Students from all over the world are welcome and supported in the work they do abroad from their home universities.

Last but not least the Bibliometrics Department is also involved in the teaching activities of the European Summer School for Scientometrics (see ad 5. Projects).

\section{Ad 2.) Consultancy and expert analyses}

The primary target group for consultancy are the researchers of the Vienna University. In order to ensure sustainability and to maximise the outreach, a service-oriented website on bibliometrics

(www.bibliometrie.univie.ac.at) has been launched in 2010. It gives an overview of the discipline's basics, shines a light on benefits as well as limits of bibliometrics, discusses current bibliometric sources, indicators and visualization methods, informs about the latest departmental activities, publications and forthcoming events, and finally provides a bibliometric glossary. This knowledge becomes more important for researchers in academia, since budgetary decisions and scientific careers are increasingly based on bibliometric input.

The website is currently available in German language only; however, parts of the content will be made translated into English in the near future.

The Bibliometric Department's staff certainly also gets in touch with the researchers directly, either addressing them proactively or responding to specific questions which range from simple issues with bibliometric databases to more sophisticated topics like publication strategy.

Furthermore the department's representatives still take an active part in the "Scientometrics" working group and directly support the Department for Quality Assurance and the rectorate. Research evaluation in academia is currently a hot topic and one of the biggest challenges in science policy decisions. Therefore a portfolio of services is provided:

- Development and performance of expert searches in bibliometric databases

- Data processing (acquisition, analysis, structuring)

- Implementation of systematic expert analyses that allow an efficient use of bibliometric methods 
- Scrutinizing value, fitness for use and interoperability of research assessment concepts including recommendations regarding their appropriate deployment and use

- Data enrichment of the research documentation system (RAD)

- Regular generation of reports

At the Vienna University the provided services are used for the periodic faculty evaluations as well as in search procedures for vacant faculty positions.

The Bibliometrics Department always aims to formulate reproducible and adjustable search strings and to perform data harvesting in a two steps approach, i.e. author and institution based. In order to accomplish the best possible correctness, authors and affiliations would finally be disambiguated manually.

In data analysis always several aspects are taken into consideration:

- Activity, i.e. the number of publications along a timeline and with differentiation of document types to reflect the productivity

- Visibility, i.e. assessment of publication sources (number of articles in peer reviewed journals, Impact Factor or alternative jounal impact measures like SJR and SNIP) to reflect the editorial barrier and to unveil publication strategies

- Impact, i.e. the number of citations incl. several citation indicators to reflect the significance in the scientific community

- Collaboration, i.e. the number of co-authors/co-affiliations to reflect national and international networking

- Scope, i.e. disciplinary vs. cross-disciplinary vs. interdisciplinary

- State-of-the-art, i.e. determination of the knowledge base according to the analysis of the references

In the course of time the outreach of the Bibliometrics Department went beyond the limits of the Vienna University, thus its expert knowledge became interesting for other national and international institutions. Responding to the demand the Bibliometrics Department started offering their services liable to charges. Among others the most prestigious contract work was done for customers like an Austrian science funding agency, a German science foundation and a German excellence university.

\section{Ad 3.) Organization of events}

Within the last 2 years the Bibliometrics Department organized several events to raise awareness for bibliometric topics. Scientists, science policy makers, university and research managers, funders and librarians were equally addressed as target audiences:

- Workshop on „InCites“ (Thomson Reuters) as well as on „SciVal Spotlight“(Elsevier) co-organized by the Department for eResource Management of the Vienna University Library

- Open Access Day co-organized by the Open Access Team of the Vienna University Library and the Department for Quality Assurance

- Bibliometric talk on „Scale-adjusted Indicators of Scientific Activity” (Science Metrix)

- Ranking Day co-organized by the Department for Quality Assurance

Moreover the Bibliometrics Department has become engaged in the organization of the main bibliometric conferences.

One of the most significant achievements was the organization of the 10th International S\&T Indicators Conference 2008 at the University of Vienna, Austria in cooperation with the Austrian Institute of Technology (AIT). The event was very successful, thus the same organizers have been assigned to host the prestigious ISSI (International Society for Scientometrics and Informetrics) Conference in Vienna in 2013.

\section{Ad 4.) Development partnerships}

Contracting development partnerships with industry is a strategic decision that makes sense especially for sophisticated and cost-intensive products. The partnering institution in academia is able to trim products according to its institutional needs and to negotiate special prices reflecting the "early adopter" status. On the other hand, industry takes advantage from the partnering institution's expert knowledge and valuable input to improve the product. Thus it is a win-win situation for both sides.

The Vienna University Library (represented by the Consortia Department, the eResource Management Department and the Bibliometrics Department) has entered into a development partnership with both InCites 
(Thomson Reuters) and SciVal Spotlight (Elsevier), trying in earnest to explore the potential of both products from a preferably neutral point of view.

Moreover the Bibliometrics Department is a supporter of the ResearcherID initiative of Thomson Reuters, aiming to normalize the affiliation and scientist names of the Vienna University in the Thomson Reuter's products in order to enhance overall data quality.

\section{Ad 5.) Projects}

The Bibliometrics Department has been engaged in a couple of national and international projects. In place of the entirety three projects shall be highlighted here.

\section{Bibliometrics Survey in Austria}

An online survey addressed to scientists from ten Austrian Universities, the Austrian Academy of Sciences as well as of the FWF Austrian Science Fund was done within the scope of a master thesis (supervised by the Bibliometrics Department) for the university course "Library and Information Studies". The analyzed results provide an insight into the awareness for bibliometrics in Austria and will first be presented at the ISSI Conference 2011 in Durban, South Africa.

\section{Open Researcher \& Contributer ID (ORCID)}

The ambiguity of scientist names and affiliations is an omnipresent and critical problem in bibliometric analyses. ORCID (http://www.orcid.org/) is an international project that aims to address this issue by establishing an open and independent registry using unique identifiers. The Bibliometric Department of the University of Vienna was one of the first universities worldwide to join this initiative.

\section{European Summer School for Scientometrics (esss)}

Scientometric procedures are increasingly used to analyze developments and trends in science and technology. Decisions to be taken often have severe implications. Consequently data handling, indicator construction and interpretation require competent expert knowledge, which is currently only available to a limited extent for all stakeholders in Central Europe not the least due to lacking training opportunities.

Responding to the lack of a pertinent scientometrics education (especially in Central Europe) and to the increasing demand (particularly of research quality managers), the University of Vienna (AT), the Humboldt University of Berlin (DE), the Institute for Research Information and Quality Assurance - iFQ - (DE) and the Katholieke Universiteit Leuven (BE) joined cooperatively to launch the European Summer School for Scientometrics (esss) (http://www.scientometrics-school.eu/) in June 2010 in Berlin (Gorraiz et al., 2011). For the first time an international, cooperative platform has been established focusing on the practical use of quantitative methods in science studies and research evaluation.

esss combines standard knowledge (state-of-the-art scientometric indicators and methods) with current trends (annually selected hot topics), presented by internationally renowned experts. Two conference-like introductory days addressing a broader audience will be followed by three days with seminars, individual hands-on sessions and teamwork in small groups.

esss is internationally orientated using English as its language of instruction, and it will be held in annual rotation at each of the organizing institutions. Meaning more than just continuing education it is also a discussion forum and an international meeting point for scientometric experts and those who aim to achieve this status. esss 2011 will be hosted by the University of Vienna from $12-16$ September, 2011.

\section{Ad 6.) Scientific Output (conference contributions and publications)}

We are currently engaged with following research topics in cooperation with several partners:

6.1) Bibliometric methods applicable for libraries

For instance an analysis of the document delivery service Subito was done to investigate the distribution of publishers and to explore the relation between the most requested journals and the most cited ones (Schloegl and Gorraiz, 2006).

6.2) Comparison and evaluation of data sources and analytical tools WoS, Scopus und Google Scholar are the major data sources for bibliometric analyses and subject of ongoing comparison for different purposes. When Scopus was launched, Vienna University was among the first comparing the sources and suggesting Scopus for bibliometric purposes (Gorraiz, 2006; Gorraiz and Schloegl, 2008). 
As mentioned before (see Development partnerships) Vienna University also contributes to the development of analytical tools like InCites and SciVal and works out library strategies for an optimum licensing, implementation and use of these products.

6.3) Development of bibliometric indicators for research evaluation (science policy) and for collection management of (e)-resources

Due to the rising costs of periodicals and the necessity of assuring access to the research results of the scientific community, new models like Open Access publishing have emerged. Many of them rely on the "author-pays" model, i.e. normally the affiliated institution covers the cost. Thus cost allocation particularly depends on how the issue of multiple authorship is addressed (either normal or fractional counting of authors and affiliations). The consequences of these two different counting approaches on the distribution of costs for multi-authored publications has been studied for the hypothetical Austrian participation in the world project SCOAP3 (Gorraiz and Wieland, 2009).

\section{4) Usage versus citation metrics}

Citation metrics are well established to assess the impact of scientific output. With the growing availability of ejournals, usage metrics have become an interesting alternative to citation metrics and allow viewing scholarly communication from the user's perspective.

The Bibliometrics Department was involved in comparative studies in this field using journals in oncology (Schloegl and Gorraiz, 2010) and in pharmacology (Schloegl and Gorraiz, 2011).

Furthermore a project called SERUM (Standardized Electronic Resource Usage Metrics) was suggested, an approach to provide global availability of usage metrics supported by libraries. The goal would be the provision of an analytical tool comparable to the Journal Citation Reports (JCR), but using download instead of citation data. Currently SERUM is only a blue sky project, however its benefits, i.e. simplicity, comprehensibility, usability and central availability are evident (Gorraiz and Gumpenberger, 2011).

6.5) Researcher and Institutions identifiers

Unique identifiers are crucial for an enhanced visibility of research institutions and the affiliated researchers. The authors have already stressed the importance of data disambiguation and pointed out their contributions to initiatives like ResearcherID and ORCID. The Bibliometrics Department advances the view that a mandatory identifier system needs to be implemented for institutions and scientists under the rule of the European Union (Gorraiz and Wieland, 2009)

6.6) Collaboration analyses

Collaboration is nowadays crucial in times of e-science and globalization. Thus the Bibliometrics Department participates in cooperative projects with an Austrian science funder as well as with SCImago. Objectives are the assessment of different types of scientific international collaboration and research on the influence of collaboration on the excellence of universities in 4 selected world regions. First results will be presented at the ISSI Conference 2011 in Durban, South Africa and at the COLLNET Conference 2011 in Istanbul, Turkey.

\section{7) Negative Results}

The importance of the publication of negative results is beyond question. Scientific progress in some disciplines is hampered by researchers' tendencies to consign negative results to the bin. However, their publication is beneficial in order to prevent duplication of effort and save public money and to facilitate and promote scientific communication. The Bibliometrics Department is therefore engaged in a cooperative research project with INIST-CNRS (Institut de l'Information Scientifique et Technique) and AIT (Austrian Institute of Technology). Objectives are the analysis of the bibliometric and semantic nature of negative results as well as the development of appropriate identification methods for negative or non-conclusive results (Gumpenberger et al., 2010).

6.8) Quantitative methods for the Social Sciences and the Humanities

In contrast to the Sciences bibliometrics is less applicable and accepted in the Social Sciences and the Humanities. The Bibliometrics department is also engaged in furthering a responsible and meaningful use and deployment of bibliometric methods and indicators in these disciplines. As an example the Bibliometrics Department contributed to a study comparing the international publication output and research impact in social sciences of the universities of Vienna, Zurich and Oslo (Gorraiz et al. 2009).

Complementing citation analysis with occurrence counting of mentions in biographical sources turned out to be a valuable quantitative method in the history of science. The Bibliometric Department is currently working on a retrospective bibliometric analysis of Francis Galton's work on the occasion of his centennial. First results have already been submitted for publication and are currently under review. 


\section{Conclusions}

Running a modern academic library in the digital era is a challenging task. It requires vision, foresight and tenacity to perceive international trends and to implement innovative solutions for all library stakeholders. The mission of an academic library is to support the university’s learning and research activities aiming

at the highest levels of international competitiveness. This is only possible by delivering high quality information services and providing guaranteed access to essential information resources. It is still an important task to remain a custodian of indispensable print collections for future generations. However, the cost-effective management of electronic resources has now become a top priority meeting the stipulation that digital content is the key driver in modern research librarianship. Information should ideally be available directly from the desktop, 24 hours a day, 7 days a week.

New core roles for academic librarians are the advancement of information literacy, optimization of the environment for students and scientists (library space dedicated to social networking), enhancement of public awareness and (inter)national cooperation, active participation in new scientific publishing trends like the Open Access movement as well as support of research assessment with high-quality bibliometric data for scientists, quality managers, deans and rectors of universities.

It is certainly important to liaise with academic staff, listen to their needs and use the librarian's subject expertise to optimize the dissemination of scholarly output. However, most academic librarians also have a degree in "Library and Information Science". Thus they are scientists per se and should therefore not simply be restricted to service providers. They should rather also actively participate in the scientific discourse and share their knowledge at conferences or via publications.

Bibliometrics is an ideal field for academic librarians to develop and provide innovative services for both academic and administrative university staff. In so doing librarians make sure to take an active part in the development of new strategies and in fostering innovation. Qualitative processes like peer-review need to be validated and are therefore increasingly complemented by quantitative methods like bibliometrics. As pointed out, librarians are predestined to fill this role and strengthen their on-campus position.

Furthermore bibliometrics and scientometrics are emerging fields in "Information Science", thus librarians should make use of their experiences gained from bibliometric services provided or projects engaged in and disseminate their findings in the scientific community.

The Bibliometrics Department of the Vienna University is fully aware of the signs of the times and has embraced both roles as a high-quality service provider as well as a contributor to scientific knowledge production. It is certainly a challenge to meet the customer requirements from the various target groups. However, once the significance of our services is understood and customers actually experience time saving through an appropriate selection of methods and data sources, our efforts will pay off and word-of-mouth recommendation will result in an increasing demand for the expertise provided.

\section{References}

Ball, R. and Tunger, D. (2004). Bibliometrische Analysen - ein neues Geschäftsfeld für Bibliotheken? B.I.T. online, 7(4), 271-278.

Cole, F. J. and Eales, N. B. (1917). The history of comparative anatomy. Part I: A statistical analysis of the literature. Science Progress, 11, 578-596.

Gerritsma, W., van Veller, M., van Zeist, C., van der Togt, P. and Leon, C. (2010). Bibliometrics in the library, putting science into practice. Book of Abstracts of the 11th Int. Conference on Science and Technology Indicators Leiden, 98.

Gorraiz, J. (2006). Web of Science versus Scopus oder Das aktuelle Dilemma der Bibliotheken. [Web of Science versus Scopus or The current dilemma of libraries.].

Mitteilungen der Vereinigung Osterreichischer Bibliothekarinnen und Bibliothekare, 59(1), 25-30.

Gorraiz, J., Gumpenberger, C. (2010). Going beyond Citations: SERUM — a new tool provided by a network of libraries. Liber Quarterly, 20, 1, 80-93, http://liber.library.uu.nl/publish/articles/000492/article.pdf

Gorraiz, J., Schloegl, C. (2008). A bibliometric analysis of pharmacology and pharmacy journals: Scopus versus Web of Science. Journal of Information Science, 34(5), 715-725.

Gorraiz, J.; Wieland, M.:(2009). Bibliometrie - eine neue Herausforderung für die Bibliotheken. 30. Österreichischer Bibliothekartag: The next Generation, Das Angebot der Bibliotheken. Graz, 17.9.2009, http://www.bibliothekartag.at/2009/nextgen/abstract20090916t03o01p01.htm

Gorraiz, J., Wieland, M. (2009). The end of barren disambiguation: Introducing an International Standard Researcher Number (ISRN) and an International Standard Institution Number (ISIN). http://phaidra.univie.ac.at/o:37899

Gorraiz, J., Wieland, M. (2009). Multi-authored publications: their influence in the distribution of the financing costs in world licenses. Research Evaluation, 18, 215-220.

Gorraiz, J., Gumpenberger, C, Mayer, W. (2010). Bibliometric practices and activities at the University of Vienna. INFORUM 2010. 16th annual Conference on Professional Information Ressources. 
May 25th - 27th 2010, Prague

http://www.inforum.cz/proceedings/2010/119

Gorraiz, J., Greil, M., Mayer, W., Reimann, R., Schiebel, E. (2009). International publication output and research impact in social sciences: comparison of the Universities of Vienna, Zurich and Oslo. Research Evaluation, 18, 221-232.

Gorraiz, J., Gumpenberger, C., Glänzel, W., Debackere, K., Hornbostel, S. and Hinze, S. (2011). esss 2010: A review of the inaugurational European Summer School for Scientometrics in Berlin. Scientometrics, Vol. 86 (1), 235-236.

Gross, P. L. K. and Gross, E. M. (1927). College libraries and chemical education. Science, 66(1713), 385-389.

Gumpenberger, C.; Besagni, D.; François, C.; Gorraiz, J.; Roche, I.; Schiebel, E.; Wieland, M. (2010). Exploring the bibliometric and semantic nature of negative results. STI Conference 2010, Leiden, 9 September 2010.

Haest, F. (2010). Evaluation of Research Performance. Is there a role for libraries? WissKom2010, Jülich, 8.-10. November 2010

MacColl, J. (2010). Library roles in university research assessment. LIBER Quarterly, 20 (2), 152-168. http://liber.library.uu.nl/publish/articles/000498/article.pdf

Schloegl, C., Gorraiz, J. (2006). Document delivery as a source for bibliometric analyses: the case of Subito. Journal of Information Science, 32(3), 223-237.

Schloegl, C. and Gorraiz, J. (2010). Comparison of citation and usage indicators: the case of oncology journals. Scientometrics, 82(3),567-580.

Schloegl, C., Gorraiz, J. (2011). Global usage versus global citation metrics: The case of pharmacology journals. Journal of the American Society for Information Science and Technology, 62 1, 161-170 